\title{
Da publicidade
}

O texto do filósofo inglês Jeremy Bentham (1748-1832) aqui apresentado corresponde à tradução do Capítulo II - intitulado "Da publicidade" - de "Um ensaio sobre táticas politicas", publicado em The works of Jeremy Bentham, da editora BookSurge Publishing, em 1791. Bentham, um dos principais expoentes do Utilitarismo, esquadrinhou categorias importantes abrigadas nas Ciências Humanas, tais como o conceito de panóptico. Neste fragmento, o filósofo se dedica a examinar o que chama de "a lei mais adequada para se assegurar a confiança pública", a saber, a lei da publicidade. É importante notar que a ideia de publicidade tem se mostrado cada vez mais proeminente para abordagens vinculadas a diferentes perspectivas nas teorias democráticas, das liberais às de cunho deliberativo ${ }^{1}$.

Antes de tratar dos detalhes acerca das operações da assembleia, deixe-nos colocar no topo de suas regulações a lei mais adequada para se assegurar a confiança pública, e provocá-la constantemente no sentido de avançar em direção ao objetivo de sua instituição.

A lei é aquela da publicidade. A discussão deste tema pode ser dividida em seis partes: 1) Razões em favor da publicidade; 2) Exame das objeções à publicidade; 3) Exceções a serem feitas; 4) Os pontos que a publicidade deveria contemplar; 5) Os métodos de publicidade; 6) Observações sobre a prática estabelecida na Inglaterra.

Nota introdutória e tradução de Francisco Jamil Marques.

- Revista Brasileira de Ciência Política, nº 6. Braślia, julho - dezembro de 2011, pp. 277-294. 


\section{Razões em favor da publicidade 1. Compelir os membros da assembleia a exercerem seu dever de ofício}

Quanto maior a quantidade de tentações às quais o exercício do poder político é exposto, mais necessário se torna dar àqueles que o possuem as mais fortes razões para resistir a elas. Não há, porém, razão mais constante e universal do que a superintendência do público. O público compõe um tribunal que é mais poderoso do que todos os outros tribunais juntos. Um indivíduo pode fingir desconsiderar seus mandatários - representá-los como se fossem formados de opiniões flutuantes e opostas, uma destruindo a outra; entretanto, cada um sente que, mesmo que este tribunal possa cometer falhas, ele é incorruptível; que ele continuamente tende a se tornar esclarecido; que o tribunal une toda a sabedoria e justiça da nação; que ele sempre decide o destino do homem público; e que as punições por ele pronunciadas são inevitáveis. Aqueles que reclamam de seus julgamentos apelam apenas a si mesmos; e o homem virtuoso, ao resistir à opinião de hoje - ao elevar ao grau mais alto o clamor geral, conta e pesa em segredo os sufrágios daqueles que a ele mesmo são semelhantes.

Caso fosse possível abstrair a si mesmo de tal tribunal, quem desejaria fazer isso? Sem dúvida, não seria nem o bom e nem o sábio homem, pois, com o tempo, estes não têm nada a temer, mas, apenas, tudo a lhes trazer esperança. Os inimigos da publicidade podem ser coligidos em três classes: os malfeitores, que buscam escapar da advertência do juiz; o tirano, que tenciona suprimir a opinião pública, enquanto teme escutar sua voz; o homem tímido ou indolente, que reclama da incapacidade geral de modo a esconder a sua própria.

Talvez possa ser dito que uma assembleia, especialmente se for numerosa, forma um público interno, que atua de modo a coagir a si mesmo. Eu retruco afirmando que uma assembleia, por mais que seja numerosa, jamais será suficientemente grande a ponto de preencher o lugar do verdadeiro público. Ela [a assembleia] será, de modo mais frequente, dividida em duas partes, que não possuirão, uma em relação à outra, as qualidades necessárias para atuarem enquanto juízes. Elas não serão imparciais. Qualquer que seja a conduta de um indivíduo, ele irá, quase sempre, estar seguro acerca dos votos de uma das partes em oposição à outra. A censura interna não será suficiente para assegurar a probidade sem a assistência de censura externa. As reprimendas dos companheiros serão um pouco tímidas, e o indivíduo 
tornar-se-á insensível àquelas feitas por seus inimigos. O espírito da parte encarcera-se dentro de limites estreitos e priva, igualmente, tanto o aplauso quanto a censura de sua natureza.

\section{Para assegurar a confiança do povo e seu consentimento às medidas da legislatura}

A desconfiança sempre se vincula ao mistério. Pensa-se ver um crime onde se enxerga uma simulação de segredo; e raramente se está enganado. Por qual motivo deveríamos nos esconder de nós mesmos se não receamos sermos vistos? Na proporção em que é desejável para a improbidade esconder a si mesma na escuridão, na mesma proporção em que é agradável à inocência caminhar num dia aberto, pelo medo de ser mal-interpretado pelo adversário. Tão clara a verdade apresenta a si mesma de uma vez às mentes das pessoas; e, caso o bom senso não tenha isso sugerido, a perversidade teria bastado para promulgá-lo. O melhor projeto arquitetado na escuridão provocaria mais alarde do que o pior empreendido sob os auspícios da publicidade.

Em uma política aberta e livre, todavia, o que a confiança e a segurança - não digo eu para o povo, mas para os próprios governantes! Dado ser impossível que qualquer coisa na nação - prove a ele que não se tenciona esconder ou surpreender - afastam-se todas as armas dos descontentes. $\mathrm{O}$ público pagará com usura a confiança que for nele depositada. A calúnia perderá sua força; ela colhe sua malevolência nas cavernas da obscuridade, mas é destruída pela luz do dia.

Uma política secreta poupa-se de algumas inconveniências, não negarei eu; porém, acredito que, com o tempo, ela cria mais [inconveniências] do que evita; e daqueles dois governos, um que deveria ser conduzido secretamente e o outro abertamente, este último possui maior força, vigor e reputação que o tornaria superior a todas as dissimulações do outro.

Considere-se, particularmente, o quanto as deliberações públicas concernentes às leis, aos padrões, às obrigações, à condução dos oficiais de estado, devam operar por sobre o espírito geral da uma nação em favor de seu governo. Objeções têm sido refutadas - falsos informantes amaldiçoados; a necessidade pelos sacrifícios requeridos do povo têm sido claramente experimentados. A oposição, não obstante seus esforços, longe de ter sido maléfica à autoridade, terá, essencialmente, contribuído com ela. É neste sentido que, conforme se tem corretamente apregoado, aquele que resiste 
fortalece; para o governo, é sem dúvida mais certeiro o sucesso geral de uma medida e a aprovação pública depois de ela ter sido discutida pelas duas partes, enquanto toda a nação tem sido espectadora.

Dentre as pessoas que já estão acostumadas às assembleias públicas, o sentimento geral será pronunciado em tom mais elevado - opiniões ressoantes serão mais comuns - lesões danosas combatidas publicamente, não por retóricos, mas por estadistas, terão menor influência. A multidão estará a salvo das artimanhas dos demagogos e das enganações dos impostores; eles conferirão maior estima aos grandes talentos, e as frivolidades dos engenhosos serão reduzidas ao seu real valor. O hábito de raciocinar e de discutir penetrará todas as classes da sociedade. As paixões, habituadas aos combates públicos, aprenderão reciprocamente a controlar a si mesmas; elas perderão uma sensibilidade mórbida, que, entre as nações sem liberdade e sem experiência, confere a elas o costume de cada alarme e de cada suspeita. Mesmo em circunstâncias nas quais os descontentes notoriamente exibem a si mesmos, os sinais do desconforto não serão sinais de revolta; a nação repousará por sobre indivíduos confiáveis a quem o antigo costume os tem ensinado a saber; e a oposição legal, a cada medida impopular, evitará a ideia de resistência ilegal. Mesmo que o desejo público esteja em oposição a uma parte consideravelmente poderosa, ele saberá que a causa não se decide sem apelo: consequentemente, persistir na paciência constitui uma das virtudes de um país livre.

A ordem que domina na discussão de uma assembleia pública constituirá, por analogia, o espírito nacional. Tal ordem será reproduzida em clubes e em assembleias inferiores, nas quais as pessoas estarão satisfeitas em encontrar a regularidade da qual eles têm formada a ideia de um grande modelo. Com qual frequência, em Londres, em meio a um tumulto efervescente, os oradores bem conhecidos não têm obtido a mesma atenção como se tivessem eles estado no parlamento? A multidão vagueou em torno deles, tem lhes escutado em silêncio, e agiu com um grau de moderação que não seria concebido mesmo em estados despóticos, nas quais o populacho, alternadamente tímido e arrogante, é igualmente desprezível em seus arrebatamentos e em sua submissão. Além disso, o regime da publicidade, entretanto - ainda imperfeito e recentemente tolerado - sem estar estabelecido em lei, não tem tido tempo para produzir todos os bons efeitos ao qual ele pode gerar. Desta forma, revoltas têm emergido, às quais não havia 
outro motivo se não a precipitação com a qual o governo atuou, sem tomar a precaução de esclarecer o povo ${ }^{2}$.

\section{Para possibilitar aos governantes conhecer os desejos dos governados}

$\mathrm{Na}$ mesma proporção em que é desejável pelos governados conhecer a conduta de seus governantes, também é importante aos governantes ter conhecimento dos reais desejos dos governados. Sob a orientação da publicidade, nada pode ser mais fácil. O público é colocado numa situação tal a ponto de poder formar uma opinião esclarecida, e o curso desta opinião é facilmente marcado. Sob o regime contrário, o que pode ser possível conhecer com certeza? O público continuará sempre falando e julgando acerca de tudo; ele julga, porém, sem informação, e mesmo fazendo uso de falsa informação; sua opinião, não estando fundamentada em fatos, é inteiramente diferente daquilo que deveria ser, do que seria, caso fosse fundada na verdade. Não se deveria acreditar que o governo pode se esbanjar na satisfação daqueles erros que teriam sido facilmente evitados. O esclarecimento tardio nem sempre repara a impressão previamente errônea. Teve o povo, do pouco que se tem divulgado em relação a um projeto, concebido percepções desastrosas? Nós os suporemos infundados; mas isto não muda a questão, eles tornaram-se agitados; eles murmuram; o alarde é propagado; a resistência é preparada. Não tem o governo mais nada a fazer além de falar - tornar a verdade conhecida, de modo a mudar o estado da mente pública? Não; sem dúvidas: a confiança se consolida lentamente. As imputações odiosas existem; as explicações que são dadas de necessidade são consideradas como reconhecimentos das fraquezas. Assim, o aperfeiçoamento de si mesmo promove um espanto quando impropriamente introduzido, e quando é oposto às inclinações do povo. A história do imperador Joseph II proveria uma variedade de exemplos.

A estas considerações maiores podem ser acostadas outras, que não deveriam ser negligenciadas.

\section{Em uma assembleia eleita pelo povo e renovada de tempos em tempos, a publicidade é absolutamente necessária para possibilitar aos eleitores agirem a partir da compreensão.}

2 Por exemplo, as rebeliões em Londres, em 1780. 
Por qual motivo renovar a assembleia se o povo sempre é obrigado a escolher dentre homens sobre quem eles nada sabem?

Esconder do público a conduta de seus representantes é tornar ainda mais inconsistente a prevaricação: é falar aos cidadãos "vocês devem eleger ou rejeitar tal ou tal dos deputados mesmo sem saber o porquê - vocês estão proibidos de fazer uso da razão - vocês devem ser guiados ao longo do exercício de seus maiores poderes pelo acaso ou pelo capricho".

\section{Uma outra razão em favor da publicidade: prover a assembleia com os recursos de benefícios obtidos a partir da informação do público}

Uma nação muito numerosa para agir por si mesma sem dúvidas se vê obrigada a confiar seus poderes aos seus representantes. Mas irão eles possuir de modo concentrado toda a inteligência nacional? É mesmo possível que os eleitos possam ser em cada aspecto os mais esclarecidos, os mais capazes e os mais sábios da nação? - que eles possuam, quando reunidos isoladamente, todo o conhecimento geral e local que a função de governar requer? Tal milagre da eleição não passa de uma quimera. Em tempos de paz, riqueza e posição distinta sempre serão as circunstâncias mais favoráveis para conciliar o maior número de votos. Os homens cujas condições em vida os levam a cultivar suas mentes raramente têm a oportunidade de entrar na carreira política. Locke, Newton, Hume, Adam Smith e outros gênios nunca tiveram um assento no parlamento. Os programas mais apropriados têm frequentemente sido perpetrados por indivíduos privados. $\mathrm{O}$ estabelecimento do fundo de amortização pelo Sr. Esmola, conforme é sabido, foi fruto dos cálculos do Dr. Preço, que nunca teria a folga requerida para tais pesquisas caso sua mente tivesse sido perturbada por atividades políticas. O único homem público que desde o início da querela com as colônias americanas teve ideias corretas acerca do assunto, e que teria salvado a nação da guerra se tivesse sido devidamente escutado, foi um clérigo excluído, graças a tal circunstância, da representação nacional ${ }^{3}$. Sem adentrar nestes detalhes, todavia, pode-se facilmente omitir o quão efetiva é a publicidade como uma forma de coletar toda a informação em uma nação, e consequentemente para se originar sugestões úteis.

Dean Tucker. 


\section{Deve-se pensar a partir das sérias considerações acerca deste tema, para avaliar as vantagens da publicidade, o deleite que dela resulta. Eu digo deleite por si mesmo, separado de instrução, ainda que, de fato, não seja possível separá-los.}

Mas aqueles que veem esta consideração como banal não raciocinam corretamente. O que eles avaliam útil é o que promete uma vantagem: o deleite é uma vantagem já contemplada; e este tipo de satisfação, em particular, a mim parece suficiente em si mesmo para aumentar a felicidade de qualquer nação que aproveitaria muito mais do que qualquer outra daquelas nações que não o conhecesse.

As memórias são uma das mais encantadoras partes da literatura francesa, e existem poucos livros que são mais profundos: as memórias, porém, não se mostram até muito depois dos eventos que elas recordam terem acontecido e não estão ao acesso de qualquer um. Os jornais ingleses são memórias publicadas no momento em que os eventos tomam lugar e no qual são encontradas todas as discussões parlamentares - tudo o que se relaciona aos atores no teatro político; no qual todos os fatos são livremente exibidos e todas as opiniões são livremente debatidas. Um dos imperadores romanos propôs uma recompensa ao indivíduo que inventasse uma nova forma de deleite: ninguém mereceu mais este prêmio do que o indivíduo que primeiro induziu as transações da assembleia legislativa perante os olhos do público ${ }^{4}$.

\section{Objeções à publicidade}

Se a publicidade é favorável aos próprios governos em tantos aspectos - de modo a assegurá-los contra a injustiça do público e para obter as melhores recompensas aos seus trabalhos - por quais motivos são eles tão inimigos deste regime? Deve esta razão ser procurada em suas depravações? no desejo do governante em agir sem responsabilidade - para livrar sua conduta de inspeção - para impor sobre o povo - para mantê-los sujeitos à sua ignorância? Tais motivos podem ser importantes; mas atribuir tudo a eles seria satírico. Pode haver erros não intencionais a este respeito, encontrados sobre objeções ilusórias: permita-nos fazer o esforço de reduzi-los ao seu real valor.

Veja-se "Paley's moral philosophy", b. vi. ch. 6, na qual este tema é tratado de modo a nada mais ser necessário adicionar. 
Primeira objeção - "O público é um juiz incompetente acerca dos procedimentos da assembleia política, em consequência da ignorância e das paixões da maioria daqueles que o compõe".

Se eu admitisse que na massa do público não pode haver um indivíduo em cem que seja capaz de formar um julgamento esclarecido acerca das questões que são discutidas em uma assembleia política, não devo eu ser acusado de enfraquecer tais objeções; além disso, mesmo a este ponto, a mim não pareceria ter [esta objeção] força alguma contra a publicidade.

Esta objeção teria alguma consistência quando os métodos de julgar corretamente fossem adotados a partir daqueles típicos do tribunal popular; a inclinação para julgar poderia ser igualmente adotada: mas o público julga e sempre julgará. Se ele devesse deter seu julgamento pelo medo de julgar incorretamente, longe de merecer ser tachado de ignorante, sua sabedoria mereceria ser admirada. Uma nação que pudesse suspender seu julgamento não seria composta de homens comuns, mas de filósofos.

Será dito que um aumento de publicações, por outro lado, aumentaria o número de maus juízes em uma proporção muito maior do que o de bons.

A isto pode ser respondido que para este propósito é necessário distinguir o público em três classes: a primeira é composta dos partidos mais numerosos, que ocupam a si mesmos muito pouco com os assuntos de concernência pública - que não tiveram tempo de ler nem de se dedicar ao raciocínio. A segunda é composta por aqueles que formam um tipo de julgamento, mas que é tomado emprestado - um julgamento fundado nas asserções dos outros, as partes nem tomando as dores necessárias, nem sendo capazes de formar uma opinião por si mesmas. A terceira é composta daqueles que julgam por si mesmos, de acordo com a informação, seja ela mais ou menos exata, que eles são aptos a conseguir.

Qual destas três classes de homens seria prejudicada pela publicidade?

Não seria a primeira, desde que, pela suposição, ela não os afetaria. É apenas a terceira: estes julgados antes - eles irão ainda julgar; mas eles julgarão mal, baseados em informações imperfeitas; eles julgarão melhor quando estiverem de posse de melhores evidências.

Enquanto acerca da segunda classe nós tenhamos dito que seus julgamentos são tomados emprestados, eles devem, desta forma, ser o eco daqueles da terceira classe. Esta classe, porém, sendo melhor informada e julgando melhor, oferecerá opiniões mais corretas àqueles que as recebam prontamente 
feitas. Ao retificá-las, você terá retificado os outros; ao purificar a fonte, você purificará os córregos.

De modo a decidir se a publicidade será maléfica ou benéfica, é necessário considerar apenas a classe que julga; porque este é o único aspecto que dirige a opinião. Mas, se uma classe julga mal, é porque ela é ignorante acerca dos fatos - porque ela não possui os pormenores necessários para formar um bom julgamento. Esta, então, é a razão dos partidários do mistério. - "Você é incapaz de julgar porque você é ignorante; e você deve permanecer ignorante já que você pode ser incapaz de julgar".

Segunda objeção - "A Publicidade pode expor ao ódio um membro da assembleia por condutas que merecem um outro tratamento".

Esta objeção desintegra a si mesma na primeira - a incapacidade do povo em distinguir entre seus amigos e seus inimigos.

Se um membro de uma assembleia política não tem firmeza suficiente para enfrentar uma injustiça momentânea, ele está carecendo da primeira qualidade de seu mandato. É característica do erro [ou de errar] possuir apenas uma existência acidental, o que pode se encerrar em um momento, enquanto a verdade é indestrutível. Ela requer apenas ser exibida, e é para tornar isso efetivo que o território da publicidade coopera. É a injustiça descoberta? - o ódio é transformado em estima; e ele que, à custa do crédito de hoje, tem ousado concorrer por reputação, é pago com juros.

Como diz respeito à reputação, a publicidade é bem mais útil aos membros de uma assembleia do que ela pode ser perniciosa: é a segurança deles contra as malignas imputações e calúnias. Não é possível atribuir a eles falsos discursos, nem esconder o bem que eles tenham feito, nem dar à sua condução uma coloração injusta. Suas intenções têm sido mal compreendidas? - uma explicação pública aniquila os falsos rumores e não deixa brechas aos ataques clandestinos.

Terceira objeção - "O desejo de popularidade pode sugerir proposições perigosas aos membros; - a eloquência que eles cultivarão será a eloquência da sedução, em vez da eloqüência da razão; - eles tornar-se-ão tribunos do povo, em vez de legisladores".

Esta objeção também dissolve a si mesma na primeira, isto é, a incompetência do povo em julgar seu real interesse, em distinguir seus amigos e seus bajuladores.

Em um estado representativo, no qual o povo não é chamado para votar acerca das medidas políticas, este perigo é minúsculo para ser temido. Os dis- 
cursos dos oradores, que ao povo é conhecido apenas através dos jornais, não têm a influência dos discursos bombásticos de um indisciplinado demagogo. Eles não o leem até depois que os discursos tenham passado através de um canal que os modere; e, além disso, eles são acompanhados pelos argumentos opostos que, de acordo com a suposição, teriam toda a vantagem natural da verdade sobre a falsidade. A publicidade dos debates tem arruinado mais demagogos do que isto tem feito. Um dileto popular tem apenas de entrar no parlamento e ele para de ser nocivo. Uma vez colocado dentre de seus iguais ou de seus superiores em talento, ele não pode afirmar nada que não será combatido: seus exageros serão reduzidos aos limites da verdade e suas presunções humilhadas, seu desejo de popularidade momentânea ridicularizado; e os bajuladores do povo acabarão por enfastiar as próprias pessoas.

Quarta objeção - "Em uma monarquia, a publicidade dos métodos das assembleias políticas, ao expor os membros da resignação do topo do estado, pode obstruir a liberdade de suas decisões”.

Esta objeção, mais ilusória do que a procedente, desaparece uma vez examinada e se prova, mesmo, um argumento a favor da publicidade. Se tal assembleia estiver em perigo da soberania, ela não tem segurança se não a proteção do povo. A segurança que emerge das deliberações secretas é mais ilusória do que real. Os métodos da assembleia seriam sempre conhecidos pelo soberano, enquanto sempre seriam desconhecidos àqueles que apenas buscam protegê-lo, se os meios a eles fossem deixados.

Se, então, uma assembleia política preferir um regime secreto, alegando a necessidade de livrar-se da inspeção do soberano, ela não deveria, então, enganar a si mesma: isto pode apenas ser fingimento. $\mathrm{O}$ verdadeiro motivo de tal conduta deve, em vez disso, estar sujeito ele mesmo à sua influência, sem muito expor a si mesmo à censura pública; porque, ao excluir o público, ele apenas livra a si mesmo da inspeção pública. O soberano não quererá seus agentes e seus espiões: ainda que invisíveis, ele estará, como esteve, presente no meio da assembléia.

Pode-se dizer contra o regime da publicidade que ele é um sistema da desconfiança? Isso é verdade; e cada boa instituição política é fundada sobre esta base. De quem nós deveríamos desconfiar se não daqueles a quem é conferida grande autoridade, com grandes tentações de abusar dela? Considere os objetos dos deveres deles [dos mandatários]: tais objetos não são seus próprios negócios, mas os negócios dos outros, comparativamente in- 
diferentes a eles, muito difíceis, muito complicados - que a apatia sozinha os levaria a negligenciar, e que requer a mais laboriosa aplicação. Considere seus interesses pessoais: você sempre irá encontrá-los em oposição aos interesses a eles confiados. Eles também possuem todos os meios para servirem a si mesmos às expensas do público, sem a possibilidade de serem condenados por isso. O que resta, então, para superar todos estes motivos perigosos? o que tem criado um interesse de força superior? e qual pode este interesse ser se não o respeito pela opinião pública - o medo de seus julgamentos - desejo de glória? - em uma palavra, tudo o que resulta da publicidade?

A eficácia deste grande instrumento se estende a tudo - legislação, administração, magistratura. Sem publicidade, nenhum bem é permanente: sob os auspícios da publicidade, mal algum pode continuar.

\section{Objetos aos quais a publicidade deveria ser estendida}

A publicação do que transita em uma assembleia política deve compreender os seguintes pontos:
1. O caráter de cada proposição.
2. O caráter dos discursos ou argumentos a favor e contra cada proposição.
3. $\mathrm{O}$ assunto de cada proposição.
4. O número de votos de cada lado.
5. Os nomes dos votantes.
6. As informações, ou seja, aquilo que tem servido como o fundamento da decisão.

Não devo eu parar de provar que o conhecimento de todos estes pontos é necessário para pôr o tribunal do público em condições de formar um julgamento esclarecido. Uma objeção, entretanto, pode ser feita contra a publicidade daquilo que correspondente ao número de votantes. Ao publicar isso, pode ser dito, a autoridade dos atos de assembleia estará em perigo de ser enfraquecida, e a oposição estará encorajada quando a maioria for pequena.

A isto pode ser retrucado que é apropriado distinguir entre oposição ilegal e legal. A primeira, digo eu, não é para ser suposta; a segunda não é um mal.

A primeira, afirmo, não é para ser suposta. A existência de um governo regulado por uma assembleia é fundada sobre uma disposição habitual em conformidade com a vontade da maioria; não se espera a unanimidade constante, porque sabe desta ser impossível; e quando uma parte é derrotada por uma pequena maioria, longe de encontrar nisto um motivo para 
uma resistência ilegal, descobre-se apenas uma razão para a esperança do sucesso futuro.

Se, posteriormente, uma oposição legal for estabelecida, isso não é mal; porque o número comparativo de votos sendo a única medida de probabilidade para a correção de suas decisões, segue-se que a oposição legal não pode ser melhor fundada do que quando guiada por tal probabilidade. Deixe-nos supor um caso de decisão judicial; - que tem havido dois julgamentos, um dado pela menor maioria possível; o outro pela maior: não seria mais natural promover um apelo contra o primeiro do que contra o segundo?

Mas a necessidade de apelo acerca de temas jurídicos não é de quase importância como nos casos de legislação. As decisões dos juízes aplicam-se apenas a casos individuais: as decisões de uma assembleia legislativa regulam os interesses de toda uma nação, e têm consequências que são continuamente renovadas.

Você espera obter maior submissão ao esconder do público as diferentes quantidades de votos? Estará enganado. O público, reduzido à suposição, desferirá seu enigma contra você. Ele será facilmente enganado por falsas informações. Uma pequena minoria pode representar a si mesma de modo quase igual à maioria e pode fazer uso de milhares de artes traiçoeiras para ludibriar o público como sua força real.

O congresso americano, durante a guerra de independência, tinha o costume, se eu não estou equivocado, de apresentar todas as suas decisões como unânimes. Seus inimigos viam nesta precaução a necessidade de esconder discordâncias habituais. Esta assembleia, em outros aspectos tão sábia, escolheu, em vez disso, expor-se a esta suspeição do que permitir que os graus de dissenso se tornassem conhecidos. Mesmo, porém, que este truque possa ter tido sucesso neste caso particular, isso não prova sua utilidade geral. $\mathrm{O}$ Congresso, seguro da confiança de seus cidadãos, empregou tal estratégia com a aprovação deles, com o propósito de confundir seus inimigos.

Os nomes dos votantes deveriam ser publicados não apenas para que o público pudesse conhecer os princípios habituais de seus representantes e sua assiduidade em servir, mas também por uma outra razão. A qualidade dos votos tem influência sobre a opinião, assim como seus números. Almejar que eles todos devam ter o mesmo valor é desejar que os tolos tenham a mesma influência dos sábios, e que o mérito deveria existir sem motivo e sem recompensa. 


\section{Exceções à regra da publicidade}

A publicidade deve ser suspensa naqueles casos nos quais ela é calculada para produzir os seguintes efeitos:

1. Favorecer os projetos de um inimigo.

2. Prejudicar desnecessariamente pessoas inocentes.

3. Impor uma punição excessivamente severa a um culpado.

Não é adequado tornar a lei da publicidade absoluta porque é impossível prever todas as circunstâncias nas quais uma assembleia pode encontrar a si mesma em seu lugar normal. As regras foram feitas para um estado de calma e segurança; elas não podem ser conformadas para um estado de problemas e sob ameaças. O segredo é um instrumento de conspiração; não deve ele, desta forma, ser um sistema regular de governo.

\section{Métodos de publicidade}

A seguir estão os métodos de publicidade que podem ser empregados tanto no todo quanto em parte para a natureza da assembleia, e a importância de seus negócios.

1. A publicação autêntica da transação da assembleia em um plano completo, incluindo os seis pontos citados no artigo precedente.

2. O emprego de escritores taquigráficos para os discursos; e, em caso de exames, para as perguntas e respostas.

3. A tolerância de outras publicações não-autênticas sobre o mesmo assunto.

4. A admissão de estranhos [à atividade discursiva] às sessões.

O emprego de escritores taquigráficos seria indispensável naqueles casos em que se fosse desejável captar o teor integral do discurso. Mas recursos não precisam ser destinados a este instrumento, exceto nas discussões de suficiente importância justificativa para este gasto. $\mathrm{Na}$ Inglaterra, em julgamento ordinário, as partes têm a liberdade de empregá-los. No julgamento solene de Warren Hastings, a Casa dos Comuns de um lado, e o acusado, de outro, tinham seus escritores taquigráficos; - a Casa dos Lordes, na qualidade de juiz, tinha também seus próprios.

Em relação às publicações não-autênticas, é necessário tolerá-las, tanto para prever negligência e desonestidade da parte dos informantes oficiais 
ou para prevenir suspeição. Um privilégio exclusivo seria visto como um certificado de falsidade. Além disso, a publicação autêntica dos procedimentos da assembleia poderia apenas ser feita com uma lentidão que não proveria satisfação pública, sem considerar o mal que emergiria a partir da diferença entre as informações falsas, antes que a publicação autêntica chegasse para destruí-las.

Periódicos não-oficiais atingiram este objetivo por completo. Seu sucesso depende da avidez do público, e seu talento consiste em satisfazê-lo. Isto tem alcançado na Inglaterra um ponto tal de celeridade que os debates têm durado até três ou quatro da madrugada e já são impressos e distribuídos na capital antes do meio dia.

A admissão do público às sessões é um ponto muito importante; este tema, entretanto, requer explicações, o que não teria lugar aqui. Isso será tratado separadamente.

A principal razão desta admissão é o que tende a inspirar confiança nas informações dos jornais. Se o público fosse excluído, ele sempre seria levado a supor que a verdade não foi informada, ou pelo menos que parte dela foi suprimida, e que muitas das coisas passadas na assembleia não se saberia. Independentemente desta garantia, todavia, está a profícua reputação dos membros da assembleia a serem ouvidos por testemunhas imparciais e julgadas por uma porção do público que é modificada a cada dia. Esta presença de estranhos é um motivo poderoso de competição entre eles, ao mesmo tempo em que é uma restrição salutar sobre as diferentes paixões às quais o debate deve fazer emergir ${ }^{5}$.

\section{O estado das coisas na Inglaterra}

De modo a fazer uma ideia adequada do estado das coisas na Inglaterra relativas à publicidade, é necessário estar atento a duas pontos bem diferentes - as regras e a prática real. A seguir estão as regras:

1. Todos os estranhos (isto é, todos os que não são membros da assembleia) estão proibidos de entrar sob pena de prisão imediata. A introdução por parte de um membro não constitui exceção à proibição, nem qualquer fundamento para se livrar da punição. Esta proibição, estabelecida durante os

Nos Cantões Suíços, estranhos não são admitidos aos debates em seus conselhos representatives, não são quaisquer observações suas publicadas. 
tempos tormentosos da guerra civil em 1650, foi renovada por sete vezes sob as circunstâncias que não oferecem nem esta desculpa nem qualquer outra ${ }^{6}$.

2. A proibição, tanto aos outros quanto aos próprios membros de reportar qualquer coisa que se passe na Casa ou de publicar qualquer coisa sem a autoridade [autorização] da Casa.

Esta regulação, que data dos primórdios da guerra civil, foi renovada trinta vezes e, pela última vez, em 1738, de um modo no qual a paixão aparenta ter carregado seu maior peso. A linguagem dos mais orgulhosos déspotas é gentil e moderada em comparação com este aspecto desta assembleia popular.

3. Desde 1722 tem sido publicado pela Casa dos Comuns o que se chama de Votos da Casa; isto é, um tipo de cronologia dos métodos, escassa e seca, contendo os relatos formais, com as moções e decisões; e, em casos de divisão, os número a favor e contra, mas sem qualquer referência aos debates.

Antes deste período, esta publicação apenas tinha lugar ocasionalmente.

Estes votos, coletados e republicados ao final do ano com uma gigantesca massa de leis públicas e atos privados, formam o que se chama de Jornais de Casa. Estes jornais eram distribuídos formalmente a cada membro, mas não chegavam a ser vendidos ao público.

4. Projetos de lei antes de serem aprovados pelo parlamento. Estes projetos, chamados de bill (projeto de lei, documento), não são impressos em regra geral, mas sua impressão é demandada sob especial moção e para uso exclusivo dos membros; desta forma, ninguém pode saber o que eles contêm a menos que se obtenha uma destas cópias privilegiadas através de um membro. Isto [uma cópia] é, entretanto, de maior importância para o público, que deveria se inteirar disso, do que para os votantes.

De todo modo, quão singular pode ser, assim, ver os representantes do povo livrarem a si mesmos de modo tão sofisticado das observações de seus cidadãos, os princípios de um governo livre são ainda pouco conhecidos, o que não tem sido uma reclamação contra a condução que tende a destruir toda a responsabilidade da parte dos representantes e toda a influência por parte da nação. 
Desde que a opinião pública, porém, mais esclarecida, tem tido maior proeminência e desde a ascensão de George III, ainda que estas regulações antipopulares continuem as mesmas, uma prática contrária tem prevalecido em muitos aspectos. Deve sem dúvidas ser lamentado que, qualquer que seja o aperfeiçoamento que tenha tido lugar na Inglaterra, ele tem sido conquistado através de uma violação contínua das leis; é gratificante, porém, observar que estas inovações tendem sutilmente à perfeição geral.

A Casa dos Comuns tem permitido a uma pequena porção do público se fazer presente em suas sessões - cerca de cento e cinquenta estranhos podem se acomodar em uma galeria separada. Infelizmente, esta generosidade é precária. Que a Casa devesse ser capaz de excluir testemunhas nos casos que nós mencionamos está correto; mas, no presente, faz-se necessário que apenas um único membro deva requerer a observação de questão de ordem que, pela força de sua natureza, é irresistível.

Assim como os conteúdos dos debates e os nomes dos votantes, existem numerosas publicações periódicas que dão conta deles. Estas publicações são crimes; é graças, porém, a estes afortunados crimes que a Inglaterra deve sua escapada de um governo aristocrático semelhante àquele de Veneza.

Tais publicações não teriam obtido este grau de indulgência se não tivessem sido mais exatas. Antigamente, caso um estranho fosse descoberto numa das galerias com um lápis em suas mãos, um clamor geral era erguido contra ele, e ele era expulso da sessão sem piedade alguma. No presente, todavia, a conivência é mais extensa e escritores taquigráficos, empregados pelos editores dos jornais do público, são tolerados.

Dentre os Lordes, as regras são quase as mesmas, mas o tom é mais moderado. Não se admite estranhos (resolução de 5 de abril de 1707). Nenhuma publicação dos debates é permitida (resolução de 27 de fevereiro de 1698). Era, entretanto, entre eles que em nossos tempos o plano de indulgência que vige atualmente foi gestado.

Esta Casa tem um costume que oferece um conjunto de suas opiniões à publicidade que não pode ser encontrado em nenhum outro exemplo.

Refiro-me aos protestos. Estas declarações, feitas por um ou por muitos membros da minoria, das razões de suas discordâncias em relação às medidas adotadas pela maioria, e inserida nos jornais. Estes protestos são impressos e circulados em oposição às regulações. Desta publicação resulta uma singularidade que deveria ser levada em consideração se as conside- 
rações estivessem contidas no interior da rotina. Isto é, as únicas razões a serem apresentadas ao público em uma forma autêntica são aquelas que estão opostas às leis.

A Casa dos Lordes, ao permitir que uma porção do público compareça às suas sessões, tem oferecido este favor de modo tão dificultoso quanto possível. Não há assentos. A primeira fileira de espectadores consegue ver e prejudica a escuta daqueles que estão mais atrás. Alguns dos membros mais populares têm, em ocasiões diferentes, proposto dar ao público mais acomodações; mas a proposição tem sempre sido recusada pela maioria de seus colegas, tanto por considerarem que uma atitude dolorosa é mais respeitosa, ou por temerem demasiadamente toda forma de mudança ${ }^{7}$.

\section{Resumo}

O objetivo do ensaio é discutir a questão da Publicidade como um princípio fundamental da política democrática. O argumento delineado leva em conta seis aspectos: 1) Razões em favor da publicidade; 2) Exame das objeções à publicidade; 3) Exceções a serem feitas; 4) Os pontos os quais a publicidade deveria contemplar; 5) Os métodos de publicidade;

7 De acordo com a Constituição Francesa de 1814, decidiu-se que "todas as deliberações da Câmara dos Iguais deveria ser secreta";

Não posso eu encontrar uma boa razão para tal segredo. Se a publicidade for perigosa, a mim parece que há menor perigo para os iguais, que estão menos expostos à ameaça da ambição popular.

A não-publicidade parece, para mim, particularmente desvantajosa aos iguais. Eles requerem a publicidade enquanto rédea e espora; enquanto rédea, porque, no mérito de sua situação, eles são pensados como tendo interesses diferentes do corpo do povo; como espora, porque eles imutavelmente enfraquecem os motivos da disputa e dão a eles uma independência absoluta.

Suponho eu que a Câmara dos Iguais é considerada como estando, ou quase para se tornar, eminentemente monárquica, como sendo um bastião da realeza contra os ataques dos representantes do povo. Mas, deste ponto de vista, não seria o segredo de suas deliberações uma tolice política? A discussão pública é permitida para aqueles que, por suposição, são inimigos da autoridade real, ou, pelo menos, bastante inclinados à democracia; e aqueles que são considerados os defensores hereditários do rei e de seus domínios estão encarcerados na discussão secreta. Esta não é uma forma de presumir que suas causas são muito fracas para sustentar a observação da nação e que para preservar os indivíduos da desaprovação geral, seria necessário que eles votassem em segredo?

Quando uma proposição na Câmara dos Deputados tem obtido grande consentimento popular, não seria desejável que os argumentos pelos quais ela tem sido oposta devessem ser conhecidos? que o corpo que a rejeitou devesse ter a correção de justificar publicamente sua recusa? que ele [o corpo que rejeitou a proposição] não deveria ser exposto à suspeita injuriosa de agir apenas com uma visão de seu próprio interesse? que ele não deveria ser colocado em tal posição desvantajosa na luta que ele tem de sustentar? O corpo que se pronuncia em público, e aqueles cujos debates são publicados, possuem todas as formas de conciliar a si mesmo partidários numerosos, enquanto aqueles que deliberam em segredo podem apenas influenciar a si mesmos. Desta forma, pareceria que este segredo, tão encatador a eles, tivesse sido inventado como um modo de tomar de sua influência sobre a opinião púbica mais do que foi dado a eles em termos de condição superior. 
6) Observações sobre a prática estabelecida na Inglaterra. Ainda que sejam identificadas ressalvas à Publicidade, considera-se tal valor indispensável ao funcionamento adequado dos regimes democráticos de governo.

Palavras-chave: publicidade; utilitarismo; teoria democrática; Bentham.

\section{Abstract}

The essay discusses the idea of publicity as a fundamental principle of democratic politics. The argument outlined takes into account the following dimensions: 1. Reasons for publicity; 2. Examination of objections to publicity; 3 . Exceptions to be made; 4 . The points to which publicity should extend; 5 . The means of publicity; 6 . Observations on the practice established in England. While some caveats can be identified regarding publicity, the excerpt proves that it is an essential value for the proper functioning of democracies.

Key-words: publicity; utilitarianism; democratic theory; Bentham. 